\title{
Chemical Composition and Biological Activities of Extracts from Pomelo Peel By-Products under Enzyme and Ultrasound-Assisted Extractions
}

\author{
Pham Van Hung $\mathbb{D}^{1},{ }^{1}$ Nguyen Hai Yen Nhi, ${ }^{1}$ Ling Yu Ting, ${ }^{1}$ and Nguyen Thi Lan Phi $\mathbb{D}^{2}$ \\ ${ }^{1}$ Department of Food Technology, International University, Vietnam National University in Ho Chi Minh City, Quarter 6, \\ Linh Trung Ward, Thu Duc District, Ho Chi Minh City, Vietnam \\ ${ }^{2}$ Department of Food Technology, University of Technology-Vietnam National University in Ho Chi Minh City, \\ 268 Ly Thuong Kiet Street, District 10, Ho Chi Minh City, Vietnam \\ Correspondence should be addressed to Pham Van Hung; pvhung@hcmiu.edu.vn and Nguyen Thi Lan Phi; nglanphi@gmail.com
} Received 24 August 2019; Revised 3 November 2019; Accepted 19 November 2019; Published 26 February 2020

Guest Editor: Abdullah Al Loman

Copyright (c) 2020 Pham Van Hung et al. This is an open access article distributed under the Creative Commons Attribution License, which permits unrestricted use, distribution, and reproduction in any medium, provided the original work is properly cited.

\begin{abstract}
Enzyme-assisted extraction (EAE) and ultrasound-assisted extraction (UAE) were popular methods used to extract bioactive compounds from citrus peels, by-products of fruit processing industry. In this study, the total phenolic content (TPC), total flavonoid content (TFC), naringin and hesperidin contents, and antioxidant and antimicrobial activities of the extracts from pomelo peels using the combined enzyme and ultrasound-assisted extraction (E-UAE) or ultrasound and enzyme-assisted extraction (U-EAE) technique were investigated and compared with those extracted using the EAE and UAE. The optimal EAE conditions were as follows: enzyme concentration of $2 \%$, water-solid ratio of $40 \mathrm{ml} / \mathrm{g}$, incubation temperature of $50^{\circ} \mathrm{C}$, and extraction time of $60 \mathrm{~min}$, whereas the optimal UAE conditions were ultrasonic energy of $40 \mathrm{kHz}$, water-solid ratio of $40 \mathrm{ml} / \mathrm{g}$ at room temperature, and extraction time of $60 \mathrm{~min}$. The results indicate that the total phenolics, total flavonoids, naringin, and hesperidin contents of the extracts significantly increased in the following order of the extraction techniques: UAE $<\mathrm{EAE}<\mathrm{U}$ EAE $<$ E-UAE $(p<0.05)$. The combined E-UAE technique was the most effective technique for bioactive compound extraction with the highest antioxidant and antimicrobial activities. The results also indicate that chemical composition and antioxidant and antimicrobial activities of the extracts were different depending on the pomelo species.
\end{abstract}

\section{Introduction}

Flavonoids, a group of pigments including flavones, flavanones, flavonols, isoflavones, anthocyanidins, and flavanols (or catechins), are present in dietary fruits and vegetables and responsible for flower and fruit coloration [1]. Flavonoids are well known for their health benefits such as antioxidative, anti-inflammatory, antimutagenic, and anticarcinogenic properties [1,2]. Pomelo (Citrus maxima), a member of the citrus family, is a native plant in tropical and semitropical countries including Vietnam. People eat fresh pomelo directly or make juices; therefore, its peel usually becomes dump without recognizing possibly nutritional value even though the pomelo's peel holds $30 \%$ of the fruit weight [3]. Pomelo peel, a by-product of fruit processing, is a rich source of flavonoids $[4,5]$, which have anti-inflammatory and anticancer characteristics and play important roles in the prevention of cardiovascular disease, diabetes, and other diseases [6]. Therefore, pomelo peels could be inexpensively and readily available resources of bioactive compounds for application in the food and pharmaceutical industries [7]. The flavonoids found in pomelo almost are flavanones $[4,5]$. Among them, naringin and hesperidin are the major compounds possessing strong antioxidant capacity, creating sweetness, and flavoring $[4,8,9]$. Nowadays, the ultrasound-assisted and enzyme-assisted extraction methods have been widely used for extracting bioactive compounds because they are considered as the innovation 
green extraction technology without using toxic solvents [10]. The enzyme-assisted extraction (EAE) techniques have been shown to improve the extraction efficiencies of antioxidant compounds including phenolics, flavonoids, anthocyanins, and carotenoids and preserve their functional properties because plant cell walls are degraded and broken down by enzymes to release bioactive compounds [11]. Likewise, the ultrasound-assisted extraction (UAE) method has been widely used because of its higher extraction efficiency with shorter extraction time compared to traditional methods [12]. Until now, most of the studies on extraction of bioactive compounds from citrus peels used either EAE or UAE technique only [13]. Therefore, the objective of this study is to investigate the effects of combined ultrasound and enzyme treatment and vice versa on total flavonoids, naringin, and hesperidin concentration, antioxidant capacity, and antimicrobial activities of extracts from peels of different pomelo species.

\section{Materials and Methods}

2.1. Materials. Da Xanh, Nam Roi, and Tan Trieu pomelos (Citrus grandis limonia Osbeck species) grown in Tien Giang, Vinh Long, and Dong Nai provinces, respectively, were used in this study. The voucher specimens of the plant were confirmed by Dr. Nguyen Thi Lan Phi of the University of Technology, VNU-HCM (No. HCMUT201, HCMUT202, and HCMUT203). Fresh pomelo fruits were collected from those provinces in December 2017 and immediately transported to the laboratory to obtain their peels. After cleaning, the green parts of the peels were peeled off, cut into small pieces (approximately $1.0 \times 1.0 \times 1.0 \mathrm{~cm}^{3}$ in dimension), and dried in the oven at $50^{\circ} \mathrm{C}$ for $24 \mathrm{~h}$ until the moisture content reached around $10 \%$. The dried peel pieces were then ground and sieved to obtain fine powder by passing through a sieve of $0.105 \mathrm{~mm}$ in aperture size. The fine powder was then kept in a desiccator until use.

The Pectinex Ultra SP-L (CAS number: 9032-75-1), commercially purchased from Novozymes, was used in this study.

\subsection{Extraction of Flavonoids from Pomelo Peels}

2.2.1. Enzyme-Assisted Extraction. Enzyme-assisted extraction (EAE) was used in this study based on the method of Jeong et al. [14] with a slight modification. The dried pomelo peel fine powder $(0.25 \mathrm{~g})$ was accurately weighed and put into a test tube with $10 \mathrm{ml}$ of distilled water, a green extraction solvent. A volume of Pectinex Ultra SP-L $(0,1,2,3$, or $4 \%$, v/w sample) was added to find out optimal enzyme concentration to extract flavonoids. The suspension was well shaken and then incubated in a shaking incubator at $50^{\circ} \mathrm{C}$ for $60 \mathrm{~min}$. After incubation, the enzyme was deactivated by boiling the suspension at $90^{\circ} \mathrm{C}$ for $5 \mathrm{~min}$, and then, the supernatant was carefully collected after centrifuging at 5,000 rpm for $10 \mathrm{~min}$.

2.2.2. Ultrasound-Assisted Extraction. Ultrasound-assisted extraction (UAE) was done based on the method of Ma et al. [15] with a slight modification. Approximately $0.25 \mathrm{~g}$ of pomelo peel powder was accurately weighed and put into a test tube with $10 \mathrm{ml}$ of distilled water. The solutions were well shaken using a vortex mixer. Then, the test tube was placed in a sonicator (WUC-A03, Daihan, India) with a frequency of $40 \mathrm{kHz}$ at room temperature and treated for 30 , 40, 50, and $60 \mathrm{~min}$ to determine the optimal time. After incubation, the test tube was then centrifuged at 5,000 rpm for $10 \mathrm{~min}$ at room temperature. The supernatant after centrifuging was quickly and carefully transferred into a new test tube and then stored in the refrigerator. All samples were carried out in triplicate.

2.2.3. Combined Extractions. In the combined method, EAE and UAE were combined in different order which was enzyme and ultrasound-assisted extraction (E-UAE) method or ultrasound and enzyme-assisted extraction (UEAE) method. The samples were extracted by EAE [14] and then by UAE [15] named as enzyme and ultrasound-assisted extraction (E-UAE) and vice versa as ultrasound and enzyme-assisted extraction (U-EAE). All samples were carried out in triplicate.

\subsection{Determination of Total Phenolic Content of the Extracts.}

The total phenolic content of extracts was determined using the Folin-Ciocalteu assay according to the report by Jeong et al. [14]. A mixture of $0.5 \mathrm{ml}$ extract, $0.5 \mathrm{ml}$ Folin-Ciocalteu reagent, and $1.0 \mathrm{ml}$ saturated sodium carbonate was added into a test tube. Then, the volume was made up to $10 \mathrm{ml}$ by distilled water and thoroughly mixed by the vortex. After incubation at room temperature in the dark for $45 \mathrm{~min}$, the tube was centrifuged at 5,000 rpm for $5 \mathrm{~min}$. The absorbance of the supernatant was measured with a spectrophotometer (Genesys 10S UV-Vis, USA) at $725 \mathrm{~nm}$. The standard curve was prepared using gallic acid solution $(20,40,60,80$, and $100 \mu \mathrm{g} / \mathrm{ml}$ ) and expressed in milligram gallic acid equivalent per gram of sample (mg GAE/g). Total phenolic content was calculated by the following equation: TPC (mg GAE/ $\mathrm{g})=\left(240.23 \times A_{s} \times \mathrm{DF}\right) / W_{s}, R^{2}=0.9991$, in which $A_{s}$ is the absorbance of the sample solution measured at $750 \mathrm{~nm}$, DF is the dilution factor, and $W_{s}$ is the mass of the sample.

\subsection{Determination of Total Flavonoids Content of the} Extracts. The total flavonoid content (TFC) was determined using the colorimetric method described by Hung and Morita [16] with a slight modification. A volume $(0.5 \mathrm{ml})$ of each extract was mixed with $1 \mathrm{ml}$ of $95 \%$ ethanol, $0.1 \mathrm{ml}$ of $1 \mathrm{M}$ potassium acetate, and $0.1 \mathrm{ml}$ of $10 \%$ aluminum chloride solutions. Then, the volume was made up to $5 \mathrm{ml}$ by distilled water. The tubes were thoroughly mixed using the vortex mixer and incubated at room temperature in the dark for $30 \mathrm{~min}$. The absorbance of solutions was measured using a spectrophotometer (Genesys 10S UV-Vis, USA) at $415 \mathrm{~nm}$. The standard curve was prepared using rutin solution and expressed in milligram rutin equivalent (RE) per gram of sample (mg RE/g). Rutin solution was diluted to $20,40,60$, 80 , and $100 \mu \mathrm{g} / \mathrm{ml}$ to form standard calibration. Total flavonoid content was calculated by the following equation: 
TFC $(\mathrm{mg} \quad \mathrm{RE} / \mathrm{g})=\left(165.2 \times A_{s} \times \mathrm{DF}\right) / W_{s}, \quad R^{2}=0.9934$, in which $A_{s}$ is the absorbance of the sample solution measured at $415 \mathrm{~nm}, \mathrm{DF}$ is the dilution factor, and $W_{s}$ is the mass of the sample.

2.5. HPLC Analysis. Flavonoid compounds including naringin and hesperidin in pomelo peel's extracts were evaluated using a HPLC method [17] with slight modification. The extracts after freeze-drying for 3 days were diluted with $5 \mathrm{ml}$ of the buffer including $0.02 \mathrm{M}$ sodium acetate buffer $(\mathrm{pH}=4)$ and methanol $(1: 1, \mathrm{v} / \mathrm{v})$. Then, the mixture was filtered through a $0.45 \mu \mathrm{m}$ membrane filter before injecting into a HPLC machine (Dionex Ultimate 3000 HPLC System, USA). The analysis was performed on a C18 column $(150 \mathrm{~mm} \times 4.6 \mathrm{~mm}, 5 \mu \mathrm{m}$ particle size; Wakosil-II 5C18 HG, Japan) with degassed mobile phase consisting of two solvents: acetonitrile $(A)$ and water $(B)$ at a flow rate of $1 \mathrm{ml} /$ min. The gradient elution was conducted as follows: $23 \% A$ in $8 \mathrm{~min}, 23-65 \% A$ in $7 \mathrm{~min}, 65-70 \% A$ in $5 \mathrm{~min}, 70-23 \% A$ in $1 \mathrm{~min}$, and at $23 \% A$ in $1 \mathrm{~min}$. The peaks were detected at $280 \mathrm{~nm}$. Naringin ( $\geq 90 \%$, from citrus fruit, code: N1376$25 \mathrm{G})$ and hesperidin ( $\geq 80 \%$, code: H5254-25G) purchased from Sigma-Aldrich Co. (Singapore) were used as standards.

2.6. DPPH Scavenging Analysis. The antioxidant activity of pomelo peel extracts was determined based on the method of Hung and Morita [16]. A volume of $0.1 \mathrm{ml}$ extract was mixed with $3.9 \mathrm{ml}$ of DPPH solution $(0.075 \mathrm{mM})$. The mixture was kept in dark at room temperature for $30 \mathrm{~min}(t=30)$. Then, the absorbance of the solution was measured immediately using a spectrophotometer (Genesys 10S UV-Vis, USA) at $515 \mathrm{~nm}$. Blank was made by mixing the DPPH solution $(3.9 \mathrm{ml})$ and $0.1 \mathrm{ml}$ of water, and the absorbance was measured at the same wavelength immediately after mixing $(t=0)$. The scavenging of DPPH was calculated as follows:

$$
\% \text { DPPH scavenging }=\left[\frac{(\operatorname{Abs}(t=0)-\operatorname{Abs}(t=30))}{\operatorname{Abs}(t=0)}\right] \times 100 .
$$

\subsection{Determination of Antimicrobial Activities}

2.7.1. Microbial Strains. There were four strains of bacteria used in this test, including Staphylococcus aureus (code: ATCC-6538 from Institute of Drug Quality Control, Ho Chi Minh), Bacillus cereus (code: VTCCB-1005 from Vietnam National University Institute of Microbiology and Biotechnology), Pseudomonas aeruginosa (code: ATCC-9027, from Institute of Drug Quality Control, Ho Chi Minh), and Salmonella typhimurium (code: ATCC-14028 Institute of Drug Quality Control, Ho Chi Minh). S. aureus and B. cereus are Gram-positive bacteria; $P$. aeruginosa and $S$. typhi are Gram-negative bacteria.

2.7.2. Diffusion Method. The agar diffusion method was used to evaluate the antimicrobial activity of extracts [18]. A $90 \mathrm{~mm}$ diameter Petri dish was filled with tryptone soybean agar (TSA, Himedia, India) to form a $3 \mathrm{~mm}$ thick agar plate. The bacteria culture $(100 \mu \mathrm{l})$ was spread on the plate and 6 wells were created: 5 wells for 5 different extract solutions and 1 well for control (without extract). The extracts were diluted with sterilized distilled water with a ratio of $1: 1$, and then, $50 \mu \mathrm{l}$ of each extract was added to the well. The control well was filled with $50 \mu \mathrm{l}$ of solvent that was used to dilute extract. After incubation at $37^{\circ} \mathrm{C}$ for $24 \mathrm{~h}$, the antimicrobial activity was evaluated by measuring the diameter of the inhibition zone in millimeter (including $6 \mathrm{~mm}$ diameter of the well) and compared with the control well.

2.8. Statistical Analysis. Analysis of variance (ANOVA) was used to analyze the data obtained from triplicate experiments to determine differences $(p<0.05)$ using the Statistical Package for the Social Sciences (SPSS).

\section{Results and Discussion}

3.1. Effect of Enzyme Concentration on Recovery of Flavonoid Content of Extract. The yields of total flavonoids extracted from pomelo peels under enzymatic treatment at different enzyme concentrations $(0,1,2,3$, and $4 \%, \mathrm{v} / \mathrm{w})$ are given in Figure 1. The total flavonoid content (TFC) increased with increasing enzyme concentration from 1 to $2 \%(\mathrm{v} / \mathrm{w})$, and the TFC of the extracts with enzymatic treatments was significantly higher than that of the control without any treatment. However, the TFC of the extracts using enzyme concentration of 3 or $4 \%$ was significantly lower than that using enzyme solution of $2 \%$. The previous study also reported that the enzymes were used to disrupt the pectin-cellulose complex in citrus peel and released higher flavonoids (naringin) in the extracts [19]. Nishad et al. [13] found that the optimized conditions for enzyme-assisted extraction of grapefruit peel were as follows: enzyme concentration of $0.9 \%$, solvent-solid ratio of $40 \mathrm{ml} / \mathrm{g}$, and extraction time of $4.81 \mathrm{~h}$. In this study, the optimal extraction conditions were as follows: enzyme concentration of $2 \%$, water-solid ratio of $40 \mathrm{ml} / \mathrm{g}$, incubation temperature of $50^{\circ} \mathrm{C}$, and extraction time of $60 \mathrm{~min}$.

\subsection{Effect of Ultrasonic Time on Recovery of Flavonoid} Content of Extract. The yields of total flavonoids extracted from pomelo peels under ultrasound treatment are shown in Figure 2. With a frequency of $40 \mathrm{kHz}$ at room temperature, the TPC of the extracts was significantly higher than that without ultrasound treatment. The TPC of the extract reached a peak at a treatment time of $50 \mathrm{~min}$. Ma et al. [15] found that both ultrasonic time and temperature enhanced the total phenolic content of the extract. However, the temperature was the most sensitive on stability of phenolic compounds. In this study, the optimal ultrasound extraction conditions were ultrasonic energy of $40 \mathrm{kHz}$, water-solid ratio of $40 \mathrm{ml} / \mathrm{g}$ at room temperature, and extraction time of $60 \mathrm{~min}$.

3.3. Bioactive Compounds of Extracts from Peels of Different Pomelo Species. Total phenolic, total flavonoid, naringin and hesperidin contents of the extracts from peels of different 


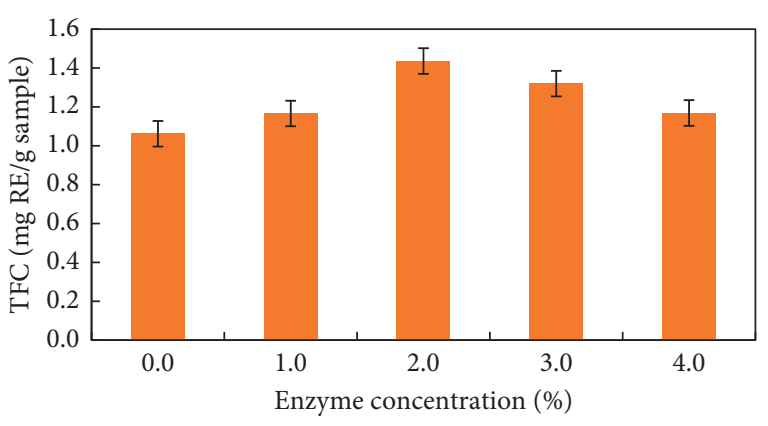

Figure 1: Effects of enzyme concentration on the recovery of total flavonoid content.

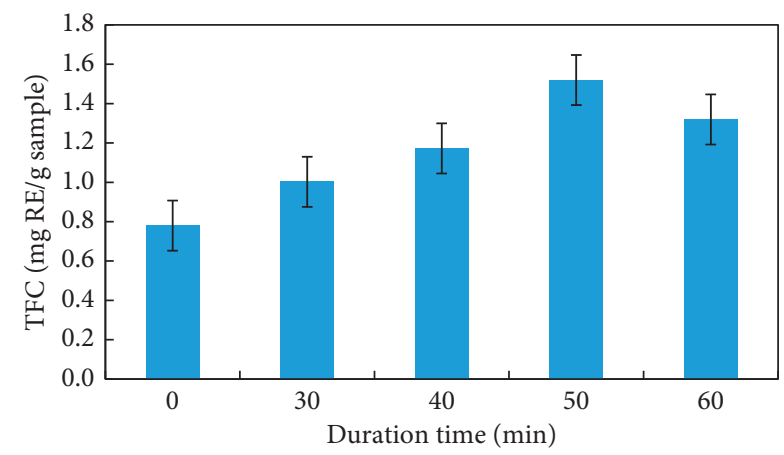

FIGURE 2: Effects of sonication time on the recovery of total flavonoid content.

pomelo species using ultrasound-assisted extraction (UAE), enzyme-assisted extraction (EAE), ultrasound and enzymeassisted extraction (U-EAE), and enzyme and ultrasoundassisted extraction (E-UAE) techniques are shown in Table 1. Total phenolic, total flavonoid, naringin, and hesperidin contents of the extracts from pomelo peels were significantly affected by extraction techniques, in which the enzyme treatment had a higher impact than the ultrasound treatment. Nishad et al. [13] also reported that EAE was more effective than UAE in extracting bioactive compounds of Citrus paradisi L. peels, similar to the results of this study. The more effective action of enzyme in releasing flavonoid compounds than ultrasonic wave might be due to the selective breakdown of the cell walls by enzyme compared to the random breakdown of cell walls by ultrasound. The results also indicated that the combined ultrasound and enzyme treatments exhibited a significantly higher impact on total flavonoid, naringin, and hesperidin contents of the extracts than the individual enzyme or ultrasound treatment. As a result, the total phenolic, total flavonoid, naringin, and hesperidin contents of the extracts significantly increased in the following order of the extraction techniques: $\mathrm{UAE}<\mathrm{EAE}<\mathrm{U}-\mathrm{EAE}<\mathrm{E}-\mathrm{UAE}(p<0.05)$. The more efficient technique in extracting the flavonoid content of mulberry must (Morus nigra) is U-EAE compared to EAE or UAE, which was also reported by Tchabo et al. [20], because the cell walls were completely broken down after double treatments.

Among the three pomelo species, Tan Trieu pomelo peels contained the highest phenolic, flavonoid, and hesperidin contents, followed by Da Xanh and Nam Roi pomelo peels. The naringin content of the Da Xanh pomelo peels was significantly higher than those of the Nam Roi and Tan Trieu pomelo peels. These results indicated that the peels of different pomelo species had different chemical compositions. Even though Tan Trieu pomelo peels had the highest TFC, the naringin content of this sample was the least. The naringin and hesperidin contents of the peels of Tan Trieu pomelo extracted using the combined enzyme and ultrasoundassisted extraction in this study were 0.99 and $0.59 \mathrm{mg} / \mathrm{g}$ sample, consistent with the results reported by $\mathrm{Wu}$ et al. [21] for the hesperidin content of pomelo peel using the ultrasound-assisted extraction with ethanol as solvent.

\subsection{Antioxidant Capacity of Extracts from Peels of Different} Pomelo Species. The antioxidant activities of extracts from pomelo peels are given in Table 2. The extract from pomelo peels using the EAE was found to have higher antioxidant activity than that using the UAE. Likewise, the extract using the combined E-UAE had stronger antioxidant activity than that using the combined U-EAE. The results of antioxidant activities also proved that the combined E-UAE technique was the most effective technique for bioactive compound extraction with the highest antioxidant activity as compared to other techniques. Among the three pomelo species, the extract from Tan Trieu pomelo peels exhibited higher antioxidant activity than the others, followed by Da Xanh pomelo peels and Nam Roi pomelo peels. Thus, the results of antioxidant activities of the extracts from pomelo peels were positively correlated with the total flavonoid contents of these extracts. Actually, in some cases, the correlation was not clear because phenolic compounds are abundant while not all of them have the antioxidative ability. Therefore, the results in this study indicated that the extracts from pomelo peels might contain almost antioxidant compounds, resulting in the positive correlation between total flavonoid content and antioxidant activity results. Ru et al. [22] also reported that the flavonoid content and antioxidant capacity of the extracts from pomelo peels were significantly different depending on the extraction techniques. In this study, the combined enzyme and ultrasound extraction was shown to be more efficient than single treatment. In addition, the flavonoid content and antioxidant capacity of the extracts were affected by pomelo species and enzyme treatment conditions.

\subsection{Antimicrobial Activities of Extracts from Peels of Different} Pomelo Species. Antimicrobial activities of the pomelo peel extracts against $S$. aureus, B. cereus, S. typhi, and P. aeruginosa were determined by diffusion method, which measured the inhibition zone in of the well on agar plate (including $6 \mathrm{~mm}$ of the well), and are shown in Table 3. The results showed that the control extracts obtained by extracting pomelo peels without any treatment did not show any inhibition against $S$. aureus, B. cereus, S. typhi, and $P$. aeruginosa (data not shown). Using UAE, the extract of $\mathrm{Da}$ Xanh pomelo peels inhibited only the $B$. cereus and that of Tan Trieu pomelo peel only exhibited the S. typhi. In contrast, the extracts obtained from pomelo peels with enzyme 
TABLE 1: Total phenolic, flavonoid, naringin, and hesperidin contents of extracts from pomelo peels using different extraction methods ${ }^{1}$

\begin{tabular}{|c|c|c|c|c|}
\hline Type of pomelo & $\begin{array}{c}\text { Total phenolics } \\
\text { (mg GAE/g sample) }\end{array}$ & $\begin{array}{l}\text { Total flavonoids } \\
\text { (mg RE/g sample) }\end{array}$ & Naringin (mg/g sample) & $\begin{array}{l}\text { Hesperidin } \\
\text { (mg/g sample) }\end{array}$ \\
\hline \multicolumn{5}{|c|}{ Ultrasound-assisted extraction } \\
\hline Da Xanh & $4.93 \pm 0.32^{\mathrm{e}}$ & $1.54 \pm 0.02^{\mathrm{ef}}$ & $1.09 \pm 0.02^{\mathrm{c}}$ & $0.23 \pm 0.01^{\mathrm{g}}$ \\
\hline Nam Roi & $4.08 \pm 0.27^{\mathrm{g}}$ & $0.93 \pm 0.03^{\mathrm{i}}$ & $0.62 \pm 0.02^{\mathrm{e}}$ & $0.13 \pm 0.01^{\mathrm{i}}$ \\
\hline Tan Trieu & $6.87 \pm 0.28^{\mathrm{b}}$ & $1.90 \pm 0.03^{\mathrm{c}}$ & $0.79 \pm 0.02^{\mathrm{f}}$ & $0.49 \pm 0.01^{\mathrm{d}}$ \\
\hline \multicolumn{5}{|c|}{ Enzyme-assisted extraction } \\
\hline Da Xanh & $6.70 \pm 0.42^{\mathrm{b}}$ & $1.60 \pm 0.01^{\mathrm{ef}}$ & $1.10 \pm 0.09^{c}$ & $0.20 \pm 0.01^{\mathrm{f}}$ \\
\hline Nam Roi & $5.65 \pm 0.20^{\mathrm{e}}$ & $0.96 \pm 0.02^{\mathrm{h}}$ & $0.68 \pm 0.04^{\mathrm{e}}$ & $0.14 \pm 0.01^{\mathrm{h}}$ \\
\hline Tan Trieu & $7.38 \pm 0.33^{\mathrm{b}}$ & $2.07 \pm 0.01^{\mathrm{b}}$ & $0.85 \pm 0.06^{\mathrm{e}}$ & $0.54 \pm 0.01^{\mathrm{c}}$ \\
\hline \multicolumn{5}{|c|}{$\begin{array}{l}\text { Ultrasound and enzyme-assisted } \\
\text { extraction }\end{array}$} \\
\hline Da Xanh & $5.76 \pm 0.06^{\mathrm{d}}$ & $1.55 \pm 0.04^{\mathrm{e}}$ & $1.04 \pm 0.09^{\mathrm{b}}$ & $0.27 \pm 0.01^{\mathrm{ef}}$ \\
\hline Nam Roi & $4.33 \pm 0.08^{\mathrm{f}}$ & $1.09 \pm 0.05^{\text {gh }}$ & $0.89 \pm 0.02^{\mathrm{de}}$ & $0.16 \pm 0.01^{\mathrm{h}}$ \\
\hline Tan Trieu & $7.06 \pm 0.15^{\mathrm{b}}$ & $2.24 \pm 0.05^{\mathrm{a}}$ & $0.87 \pm 0.09^{\mathrm{de}}$ & $0.54 \pm 0.01^{\mathrm{b}}$ \\
\hline \multicolumn{5}{|c|}{$\begin{array}{l}\text { Enzyme and ultrasound-assisted } \\
\text { extraction }\end{array}$} \\
\hline Da Xanh & $7.16 \pm 0.12^{\mathrm{b}}$ & $1.76 \pm 0.06^{\mathrm{d}}$ & $1.15 \pm 0.07^{\mathrm{a}}$ & $0.29 \pm 0.01^{\mathrm{e}}$ \\
\hline Nam Roi & $6.03 \pm 0.25^{\mathrm{c}}$ & $1.15 \pm 0.04^{\mathrm{g}}$ & $1.04 \pm 0.01^{\mathrm{d}}$ & $0.16 \pm 0.01^{\mathrm{g}}$ \\
\hline Tan Trieu & $7.50 \pm 0.28^{\mathrm{a}}$ & $2.29 \pm 0.05^{\mathrm{a}}$ & $0.99 \pm 0.01^{\mathrm{d}}$ & $0.59 \pm 0.01^{\mathrm{a}}$ \\
\hline
\end{tabular}

${ }^{1}$ Values followed by the same superscript letters in the same column are not significantly different $(p<0.05)$.

TABLE 2: DPPH scavenging capacity (\%) of extracts from pomelo peels ${ }^{1}$.

\begin{tabular}{lccc}
\hline Extraction methods & Da Xanh & Nam Roi & Tan Trieu \\
\hline UAE & $23.6 \pm 1.0^{\mathrm{e}}$ & $13.7 \pm 0.7^{\mathrm{g}}$ & $34.8 \pm 1.1^{\mathrm{bc}}$ \\
EAE & $28.6 \pm 1.1^{\mathrm{d}}$ & $23.2 \pm 0.8^{\mathrm{e}}$ & $42.5 \pm 1.0^{\mathrm{a}}$ \\
U-EAE & $25.8 \pm 0.7^{\mathrm{e}}$ & $17.1 \pm 0.6^{\mathrm{f}}$ & $36.9 \pm 0.6^{\mathrm{b}}$ \\
E-UAE & $32.3 \pm 0.5^{\mathrm{c}}$ & $24.0 \pm 0.7^{\mathrm{e}}$ & $43.3 \pm 1.6^{\mathrm{a}}$ \\
\hline
\end{tabular}

UAE, ultrasound-assisted extraction method; EAE, enzyme-assisted extraction method; U-EAE, ultrasound and enzyme-assisted extraction method; E-UAE, enzyme and ultrasound-assisted extraction method. ${ }^{1}$ Data (mean \pm standard deviation) followed by the same superscript letters in the same column are not significantly different $(p<0.05)$.

TABle 3: Antimicrobial activities of extracts from pomelo peels using different extraction methods ${ }^{1}$.

\begin{tabular}{|c|c|c|c|c|}
\hline \multirow{2}{*}{ Type of pomelo } & \multicolumn{4}{|c|}{ Diameter of inhibition (mm) } \\
\hline & S. aureus & B. cereus & S. typhi & P. aeruginosa \\
\hline \multicolumn{5}{|c|}{ Ultrasound-assisted extraction } \\
\hline Da Xanh & nd & $10.7 \pm 0.6^{\mathrm{a}}$ & nd & nd \\
\hline Nam Roi & nd & nd & nd & nd \\
\hline Tan Trieu & nd & nd & $8.3 \pm 0.6^{\mathrm{a}}$ & nd \\
\hline \multicolumn{5}{|c|}{ Enzyme-assisted extraction } \\
\hline Da Xanh & $8.3 \pm 0.6^{\mathrm{a}}$ & $10.7 \pm 0.6^{\mathrm{a}}$ & $10.7 \pm 1.5^{\mathrm{b}}$ & $10.3 \pm 0.6^{\mathrm{b}}$ \\
\hline Nam Roi & $12.3 \pm 1.5^{\mathrm{c}}$ & $10.7 \pm 0.6^{\mathrm{a}}$ & $10.0 \pm 1.0^{\mathrm{b}}$ & $11.0 \pm 1.0^{\mathrm{bc}}$ \\
\hline Tan Trieu & $7.7 \pm 0.6^{\mathrm{a}}$ & $10.0 \pm 1.0^{\mathrm{a}}$ & $8.3 \pm 0.6^{\mathrm{a}}$ & $8.0 \pm 1.0^{\mathrm{a}}$ \\
\hline \multicolumn{5}{|c|}{ Ultrasound and enzyme-assisted extraction } \\
\hline Da Xanh & $8.7 \pm 0.6^{\mathrm{a}}$ & $11.7 \pm 0.6^{\mathrm{ab}}$ & $10.0 \pm 2.0^{\mathrm{b}}$ & $10.7 \pm 0.6^{\mathrm{b}}$ \\
\hline Nam Roi & $11.7 \pm 1.2^{\mathrm{bc}}$ & $11.3 \pm 0.6^{\mathrm{ab}}$ & $9.3 \pm 1.2^{\mathrm{ab}}$ & $10.7 \pm 1.2^{\mathrm{b}}$ \\
\hline Tan Trieu & $7.3 \pm 0.6^{\mathrm{a}}$ & $11.3 \pm 0.6^{\mathrm{ab}}$ & $10.3 \pm 1.5^{\mathrm{b}}$ & $9.0 \pm 1.0^{\mathrm{ab}}$ \\
\hline \multicolumn{5}{|c|}{ Enzyme and ultrasound-assisted extraction } \\
\hline Da Xanh & $10.7 \pm 0.6^{\mathrm{b}}$ & $11.3 \pm 0.6^{\mathrm{ab}}$ & $10.0 \pm 2.0^{\mathrm{b}}$ & $8.0 \pm 1.0^{\mathrm{a}}$ \\
\hline Nam Roi & $12.3 \pm 0.6^{\mathrm{c}}$ & $12.0 \pm 0.1^{\mathrm{b}}$ & $11.3 \pm 0.6^{\mathrm{c}}$ & $12.3 \pm 0.6^{\mathrm{c}}$ \\
\hline Tan Trieu & $10.7 \pm 0.6^{\mathrm{b}}$ & $10.7 \pm 0.6^{\mathrm{a}}$ & $10.3 \pm 0.6^{\mathrm{b}}$ & $9.3 \pm 1.5^{\mathrm{ab}}$ \\
\hline
\end{tabular}

nd, not detected. ${ }^{1}$ Data (mean \pm standard deviation) followed by the same superscript letters in the same column are not significantly different $(p<0.05)$.

treatments (EAE, U-EAE, and E-UAE) exhibited positive antimicrobial activities against all types of bacteria. There was no significant difference in antimicrobial capacities of the extracts from pomelo peels obtained using the EAE and U-EAE techniques, while the stronger antimicrobial capacities of the extracts using the E-UAE were observed. The 
results also indicated that the antimicrobial activities of the extracts from pomelo peels against four bacteria were not significantly different, while the extract of Nam Roi pomelo peels exhibited higher antimicrobial activities than the other pomelo species. The results in this study are consistent with the results of Abirami et al. [23], who reported that the crude extracts of pomelo peels using the conventional methanol extraction had antimicrobial activities of around $8 \mathrm{~mm}$ to $10 \mathrm{~mm}$ (including $5 \mathrm{~mm}$ paper disc) against $S$. aureus, S. typhi, and $P$. aeruginosa. Another research showed that the inhibition zone of the crude extracts using the conventional solvent extraction (dichloromethane, hexane, or ethyl acetate) was between $7.54 \mathrm{~mm}$ and $8.83 \mathrm{~mm}$ (including disc paper of $6 \mathrm{~mm}$ ) against $S$. aureus [24]. Thus, the extraction techniques in this study using the combined enzyme and ultrasound treatment for extracting the bioactive compounds from the pomelo peels had more advantages with high antimicrobial activities and considered as the innovation green extraction technology without using toxic solvents.

\section{Conclusion}

In this study, enzyme-assisted and ultrasound-assisted extraction or their combination processes were carried out to extract the bioactive compounds from peels of three kinds of pomelos in Vietnam. The results indicated that the enzyme treatment had more impact on releasing the bioactive compounds than the ultrasound treatment. The E-UAE was found to be the most effective technique to obtain the extracts having the highest TPC, TFC, naringin, and hesperidin contents and antioxidant and antimicrobial activities compared to other extraction techniques. The results also indicated that Tan Trieu pomelo contains the higher TPC and TFC contents and antioxidant and antimicrobial activities than Da Xanh and Nam Roi pomelo species. Moreover, this research focused on "green" solution for the environment: using water as a solvent and taking all advantages of "waste."

\section{Data Availability}

No data were used to support this study.

\section{Conflicts of Interest}

The authors declare no conflicts of interest.

\section{Acknowledgments}

This research was funded by Vietnam National University in Ho Chi Minh City (VNU-HCM) (grant no. B2019-20-04). The authors also thank Vietnam National Foundation for Science and Technology Development (NAFOSTED) for their financial support (grant no. 106-NN.02-2016.72).

\section{References}

[1] J. Peterson and J. Dwyer, "Flavonoids: dietary occurrence and biochemical activity," Nutrition Research, vol. 18, no. 12, pp. 1995-2018, 1998.
[2] A. N. Panche, A. D. Diwan, and S. R. Chandra, "Flavonoids: an overview," Journal of Nutritional Science, vol. 5, no. e47, pp. 1-15, 2016.

[3] Z. Zarina and S. Y. Tan, "Determination of flavonoids in Citrus grandis (pomelo) peels and their inhibition activity on lipid peroxidation in fish tissue," International Food Research Journal, vol. 20, no. 1, pp. 313-317, 2013.

[4] K. Zunli, P. Yu, X. Xiaodan, N. Chao, and Z. Zhiqin, "Citrus flavonoids and human cancers," Journal of Food and Nutrition Research, vol. 3, no. 5, pp. 341-351, 2015.

[5] J. J. Peterson, J. T. Dwyer, G. R. Beecher et al., "Flavanones in oranges, tangerines (mandarins), tangors, and tangelos: a compilation and review of the data from the analytical literature," Journal of Food Composition and Analysis, vol. 19, pp. S66-S73, 2006.

[6] L. Yi, S. Ma, and D. Ren, "Phytochemistry and bioactivity of citrus flavonoids: a focus on antioxidant, anti-inflammatory, anticancer and cardiovascular protection activities," Phytochemistry Reviews, vol. 16, no. 3, pp. 479-511, 2017.

[7] G.-F. Deng, C. Shen, X.-R. Xu et al., "Potential of fruit wastes as natural resources of bioactive compounds," International Journal of Molecular Sciences, vol. 13, no. 7, pp. 8308-8323, 2012.

[8] Y. Nogata, K. Sakamoto, H. Shiratsuchi, T. Ishii, M. Yano, and H. Ohta, "Flavonoid composition of fruit tissues of citrus species," Bioscience, Biotechnology, and Biochemistry, vol. 70, no. 1, pp. 178-192, 2006.

[9] Z. Zou, W. Xi, Y. Hu, C. Nie, and Z. Zhou, "Antioxidant activity of citrus fruits,” Food Chemistry, vol. 196, pp. 885-896, 2016.

[10] M. Puri, D. Sharma, and C. J. Barrow, "Enzyme-assisted extraction of bioactives from plants," Trends in Biotechnology, vol. 30, no. 1, pp. 37-44, 2012.

[11] D.-P. Xu, Y. Li, X. Meng et al., "Natural antioxidants in foods and medicinal plants: extraction, assessment and resources," International Journal of Molecular Sciences, vol. 18, no. 1, p. 96, 2017.

[12] N. M'hiri, I. Ioannou, M. Ghoul, and N. M. Boudhrioua, "Extraction methods of citrus peel phenolic compounds," Food Reviews International, vol. 30, no. 4, pp. 265-290, 2014.

[13] J. Nishad, S. Saha, A. K. Dubey, E. Varghese, and C. Kaur, "Optimization and comparison of non-conventional extraction technologies for Citrus paradisi L. peels: a valorization approach," Journal of Food Science and Technology, vol. 56, no. 3, pp. 1221-1233, 2019.

[14] S.-M. Jeong, S.-Y. Kim, D.-R. Kim et al., "Effect of heat treatment on the antioxidant activity of extracts from citrus peels," Journal of Agricultural and Food Chemistry, vol. 52, no. 11, pp. 3389-3393, 2004.

[15] Y. Ma, J. Chen, D. Liu, and X. Ye, "Simultaneous extraction of phenolic compounds of citrus peel extracts: effect of ultrasound," Ultrasonics Sonochemistry, vol. 16, no. 1, pp. 57-62, 2009.

[16] P. V. Hung and N. Morita, "Distribution of phenolic compounds in the graded flours milled from whole buckwheat grains and their antioxidant capacities," Food Chemistry, vol. 109, no. 2, pp. 325-331, 2008.

[17] A. R. Isabel and R. Maria, "Naringin and naringenin determination and control in grapefruit juice by a validated HPLC method," Food Control, vol. 19, no. 4, pp. 432-438, 2008.

[18] National Committee for Clinical Laboratory Standards, Performance Standards for Antimicrobial Disk Susceptibility Tests, vol. 17, National Committee for Clinical Laboratory Standards, Wayne, PA, USA, 6th edition, 1997. 
[19] M. Puri, A. Kaur, W. H. Schwarz, S. Singh, and J. F. Kennedy, "Molecular characterization and enzymatic hydrolysis of naringin extracted from kinnow peel waste," International Journal of Biological Macromolecules, vol. 48, no. 1, pp. 58-62, 2011.

[20] W. Tchabo, Y. Ma, F. N. Engmann, and H. Zhang, "Ultrasound-assisted enzymatic extraction (UAEE) of phytochemical compounds from mulberry (Morus nigra) must and optimization study using response surface methodology," Industrial Crops and Products, vol. 63, pp. 214-225, 2015.

[21] T. Wu, Y. Guan, and J. Ye, "Determination of flavonoids and ascorbic acid in grapefruit peel and juice by capillary electrophoresis with electrochemical detection," Food Chemistry, vol. 100, no. 4, pp. 1573-1579, 2007.

[22] Q. M. Ru, R. F. Cai, and J. Z. He, "Comparison of different extraction methods for antioxidant property of flavonoids from pomelo peel," Advanced Materials Research, vol. 652-654, pp. 443-448, 2013.

[23] A. Abirami, G. Nagarani, and P. Siddhuraju, "Antimicrobial activity of crude extract of Citrus hystrix and Citrus maxima," International Journal of Pharmaceutical Science and Research, vol. 4, pp. 1-5, 2013.

[24] S. Aichayawanich and C. Ngaowthong, "Antimicrobial activity of crude extract from pomelo peel against Staphylococcus aureus," Advanced Materials Research, vol. 550-553, pp. 1871-1874, 2012. 